\title{
Enhancement of Students' Recognition for Fundamental Competency Factors through Extra-Curricular Project Activities in University
}

\author{
Masahisa Shinoda and Keita Nishioka
}

\begin{abstract}
Enhancement of students' recognition for fundamental competency factors through extra-curricular project activities is introduced. Special ideas or tools should be required to success projects, since students are beginners for project activities. Therefore, achievement abilities are important to proceed with projects as well as a methodology of project management. To satisfy this requirement, an idea of "Fundamental Competencies for Working Person", that was defined by the ministry of Economy, Trade and Industry in Japan in 2007, is tried to apply into the project activities. A change of students' recognition from the viewpoint of the above definition through the project activities are studied. The results of questionnaire at the end of the project term show that the students' recognition for fundamental competency factors was improved by experiencing the project activities, and that they felt the importance of competency factors described in this definition.
\end{abstract}

Index Terms-Project management, project activity in university, fundamental competencies for working persons, extra-curricular program, systematization.

\section{INTRODUCTION}

Kanazawa Institute of Technology (KIT) has a wide variety of facilities and unique environment to support project activities as extra-curricular programs. Total number of project activities that are recognized officially at KIT is 82 in 2018. Manufacturing robots and hand aircrafts aiming at contests are the typical examples. Professors and lecturers belonging to KIT are making various efforts to improve these project activities [1]-[4]. Similar projects and these analysis were also performed in other universities [5], [6].

We are directing the project based on fundamental science and engineering, which is one of the officially recognized projects at KIT and the extra-curricular program. We are also studying how to improve the quality of both a process and a product through each project activity. Prof. M. Shinoda, one of the author, moved to KIT from the electric manufacturing company in 2015. He has a wide variety of experiences about designing and manufacturing electric appliances, for examples, DVD player/recorder, Blu-ray player/recorder, and liquid crystal displays. He has been also certified as PMP (Project Management Professional) by Project Management

Manuscript received December, 15, 2018; revised May 4, 2019. This work was supported by JSPS KAKENHI Grant Number 16K01039.

The authors are with the Mathematics and Science Education Research Center, Kanazawa Institute of Technology, Nonoichi, Ishikawa 921-8501, Japan (e-mail: shinoda@neptune.kanazawa-it.ac.jp, knisi@neptune.kanazawa-it.ac.jp).
Institute (PMI) since 2007. With these points as backgrounds, we are tackling with the projects based on fundamental science and engineering to improve the quality of both the product and the process of each project by applying the well-known method of project management [7], [8]. This method was established and published as "A guide to the project management body of knowledge", so called as "PMBOK GUIDE", [9]. This is practically defined as a useful methodology to guide the project activities to their goals. Therefore, we have been trying to apply this guide book to the projects.

On one hand, the ministry of Economy, Trade and Industry (METI) in Japan defined the basic abilities required in working together with various people in the workplace and in the local communities as "Fundamental Competencies for Working Person" in 2007 [10]. This definition consists of three competencies at a committee comprising of intellectuals in the businesses and universities. Each competency includes several competency factors. Since, these competencies are necessary to start a working person, university students should acquire them by their graduation.

We started to examine whether this definition for working person becomes a driving force to proceed with the project activities [11]. We introduced the annual project plan format and the bi-weekly report format, which were considered by both "PMBOK GUIDE" and "Fundamental Competencies for Working Person". Using these formats, the students think deeply of their projects on items such as purposes, outputs, schedule, progress, problems, risks, and so on. These items are also important for the teaching staff to control the project activities. Thus, we were trying to enhance the project students' mind to succeed their projects.

In this paper, the results how "Fundamental Competencies for Working Person" affected the students' recognition through their project activities is introduced.

\section{BRIEF INTRODUCTION OF THE FUNDAMENTAL SCIENCE AND ENGINEERING PROJECT}

In the fundamental science and engineering project that we are directing, the students propose project subjects individually. Next, the students and the teaching staff verify the principle of each proposed subject from the standpoints of mathematics, physics, engineering, electronics, software programing, production, and so on. After that, the students proceed to manufacture their products of project subjects. Typical project term is one year.

Fig. 1 shows one example of products, the milling machine. 
The fourth grade student majoring mechanics engineering designed and manufactured it by himself as a tool for his hobby. Through this project activity, he acquired a skill of designing using 3D-CAD and of manufacturing using a turning lathe, a drilling machine, and a milling machine. He also learned that planning and making a schedule in detail was very important to manufacture the product as well as academic ability and technical skill.

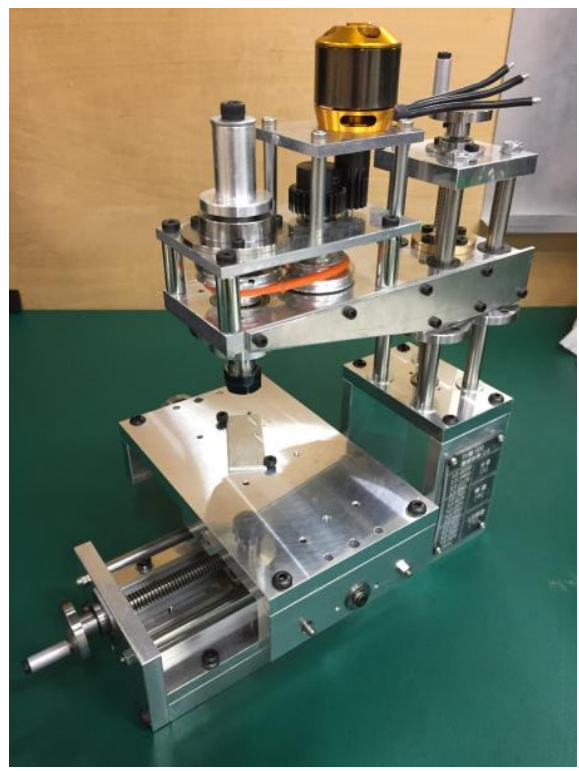

Fig. 1. An example of products, the milling machine, which was proceeded by the fundamental science and engineering project activity.

\section{NEW APPROACH TO ENHANCE STUdENTS' RECOGNITION FOR FUNDAMENTAL COMPETENCY FACTORS}

\section{A. Brief Introduction of "Fundamental Competencies for Working Person"}

As mentioned in Sec. I, "Fundamental Competencies for Working Person" was defined by METI in 2007 [10]. Fig. 2 shows the details of this definition. This definition consists of three competencies, "Thinking", "Action", and "Teamwork". "Thinking" is ability to question and think through, and includes three competency factors. "Action" is ability to step forward and act persistently even if you fail, and includes three competency factors. "Teamwork" is ability to collaborate with various people to achieve goals, and includes six competency factors.

\section{B. New Approach to Enhance Students' Recognition for Fundamental Competencies}

We were convinced that this definition was applicable to introduce to the projects, especially extra-curricular programs in which students with various grade and special study gather, and that this definition became a driving force to proceed with the projects. The competencies described in this definition are seemed to enhance the students' recognition for their project activities.

Therefore, we frequently made the project students aware of "Fundamental Competencies for Working Person". All students understood the importance of this definition and proceeded with their own project activities. At the end of the project term, we examined the results how this definition affected the students' recognition through their project activities.

$$
\begin{aligned}
& \text { (A) Thinking = Ability to think through } \\
& \text { - Ability to question and think through - } \\
& \text { 3 Competency Factors }
\end{aligned}
$$

\section{Competency Factors}

\begin{tabular}{|l|}
\hline A1 : Ability to detect issues \\
A2 : Planning skill \\
A3 : Creativity
\end{tabular}

(B) Action = Ability to step forward

- Ability to step forward and act persistently even if you fail -

\section{Competency Factors}

B1 : Initiative

B2 : Ability to influence

B3 : Execution skill

\section{(C) Teamwork $=$ Ability to work in a team \\ - Ability to collaborate with various people to achieve goals -}

\section{Competency Factors}

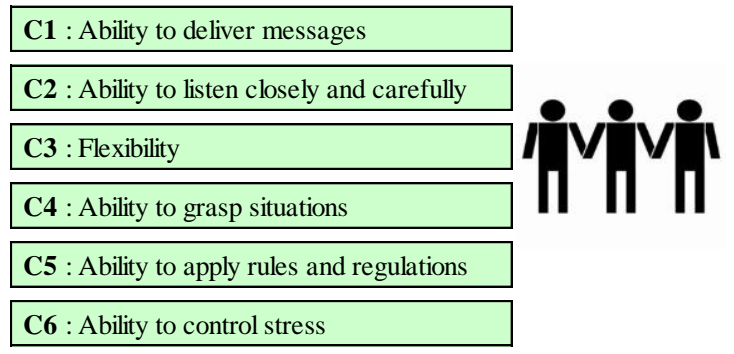

Fig. 2. "Fundamental Competencies for Working Person" defined by METI in 2007. (This figure is re-drawn by the author according to METI's web site).

\section{RESULTS OF STUDENTS' RECOGNITION FOR FUNDAMENTAL COMPETENCY FACTORS FOR WORKING PERSONS}

\section{A. Students' Actual Recognition for "Fundamental Competencies" through the Project Activities}

We evaluated the students' recognition for "Fundamental Competencies" through the project activities by a questionnaire at the end of the project term in 2017.

Question 1) Choose best five factors which you acquire through the project activity from the top.

Fig. 3(a) is the result of question 1. Best factor is weighted with 5 point, second best factor is weighted with 4 point, and in the same way, fifth best factor is weighted with 1 point. The vertical number means total points. "(A1) Ability to detect issues", "(A3) Creativity", and "(B3) Execution skill” acquired high points. These factors are seemed to be main interests for the project students. On the other hand, "(B1) Initiative" and "(B2) Ability to influence" did not acquire high points. From this result, the students' attitude during 
project activities seems to be not aggressive. As for competency categories, "Teamwork" acquired smaller points than "Thinking" and "Action". "(B1) Initiative" and "(B2) Ability to influence" are closely related to "Teamwork". Actually, most of project activities were proceeded by single student. This seems to be the reason that the competencies related to "Teamwork" did not the driving force to enhance the students' recognition to perform the project activities.

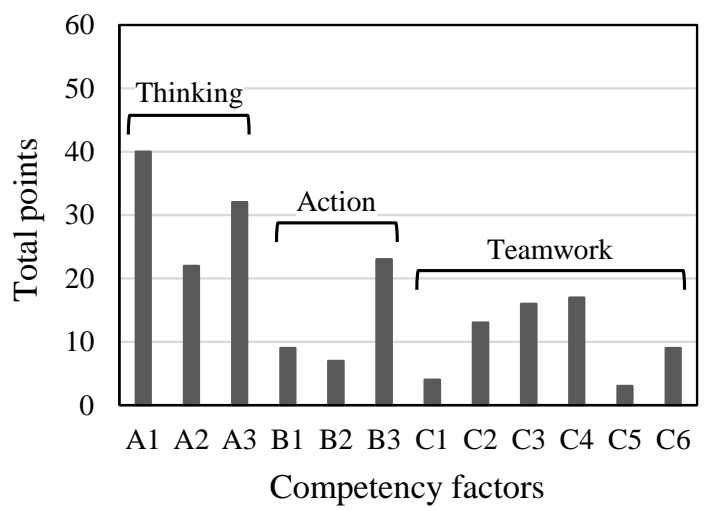

(a) Best five factors which the project students acquired through the project activity.

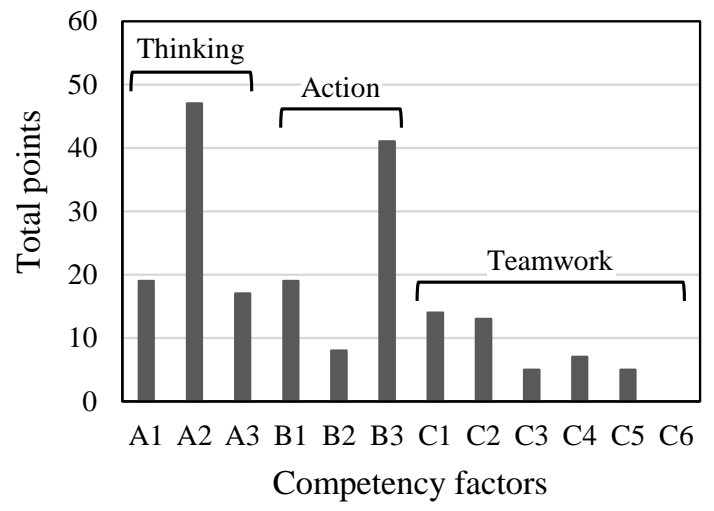

(b) Best five factors which the project students want to acquire in the near future from the last project experience.

[Symbols of the horizontal axes]
A1 : Ability to detect issues
A2 : Planning skill
A3 : Creativity
B1 : Initiative
B2: Ability to influence
B3: Execution skill
C1 : Ability to deliver message
C2: Ability to listen closely and carefully
C3: Flexibility
C4: Ability to grasp situation
C5: Ability to apply rules and regulations
C6: Ability to control stress

Fig. 3. Change of students' recognition for "fundamental competencies" through the project activities.

Question 2) Choose best five factors which you want to acquire in the near future from the last project experience from the top.

Fig. 3(b) is the result of question 2. The vertical number means total points as well as Fig. 3(a). "(A2) Planning skill” and "(B3) Execution skill" overwhelmingly acquired high points. These factors are seemed to be main skills to manufacture the product. From these results, the project students recognized the lack of careful plans during their project activities. Also, they strongly wanted to acquire execution skill to improve their products with respect to quality.

B. Change of the Students' Recognition for "Fundamental Competencies" from the Project Experience

As for "Thinking" and "Action" competency, we also investigated the change of recognition level of the project students from before project (PJT) to after PJT.

Fig. 4 shows the results for the competency "Thinking".

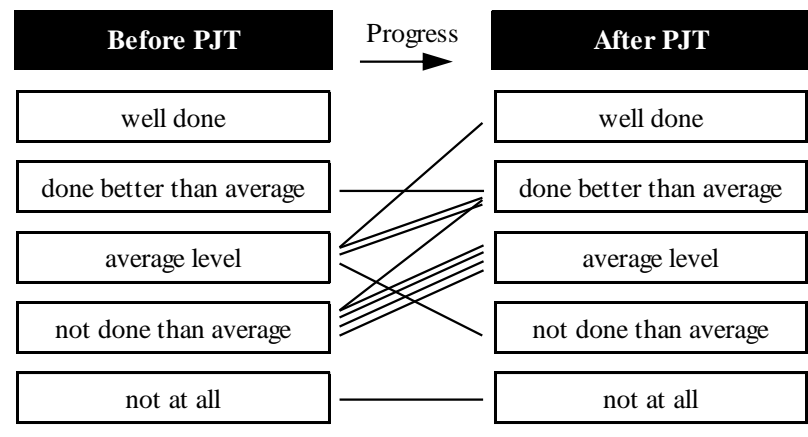

(a) A1: Ability to detect issues.

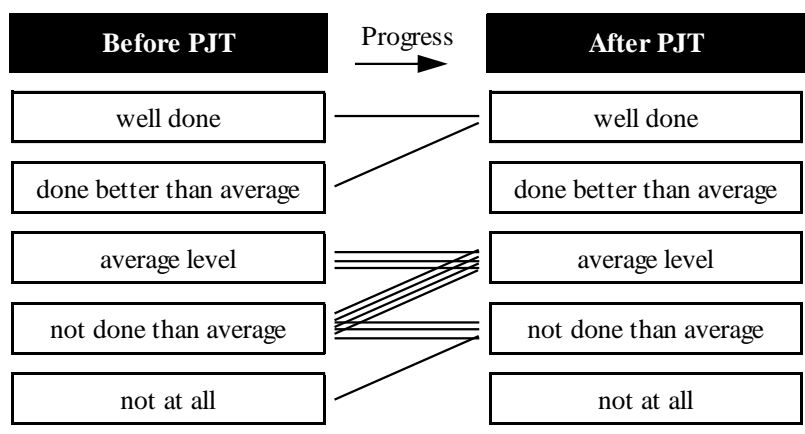

(b) A2: Planning skill.

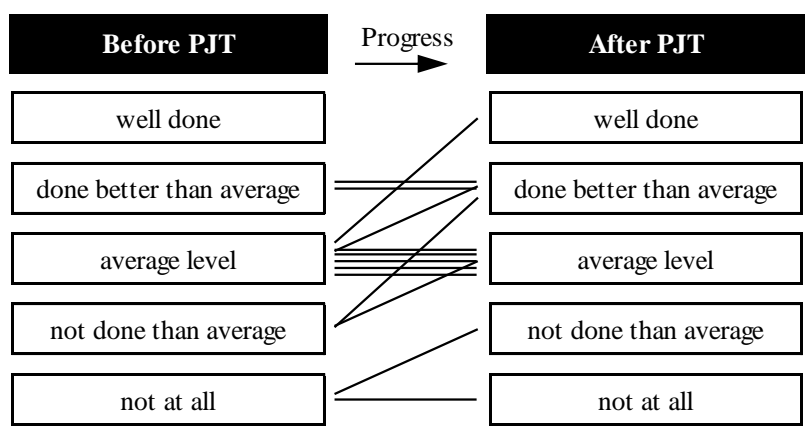

(c) A3: Creativity.

Fig. 4. Change of students' recognition for "thinking" competency.

In all competency factors, initial recognitions of most of students were average or lower levels before project. After project, however, most of their level increased by one or two level with respect to "A1: Ability to detect issues" and "A2: Planning skill". As for "A3: Creativity", more than half of students recognized no definite level-up after project. Generally, the students actually recognized that they improved themselves to proceed with their project activities with respect to "Thinking" competency.

Fig. 5 shows the results for "Action" competency. Generally, the tendency of the change was the same as that of "Thinking" competency. But, a noteworthy result was obtained for "B3: Execution skill". Almost students recognized that their execution skills were not enough at the 
beginning of the project, because all students were beginners for project activities. However, after the project, they recognized certain improvement of execution skills. Each student struggled how to plan a schedule, how to manufacture a product, how to evaluate it, and son on, for the first time during the project activities. This seems to be the reason that "B3: Execution skill" acquired high points.

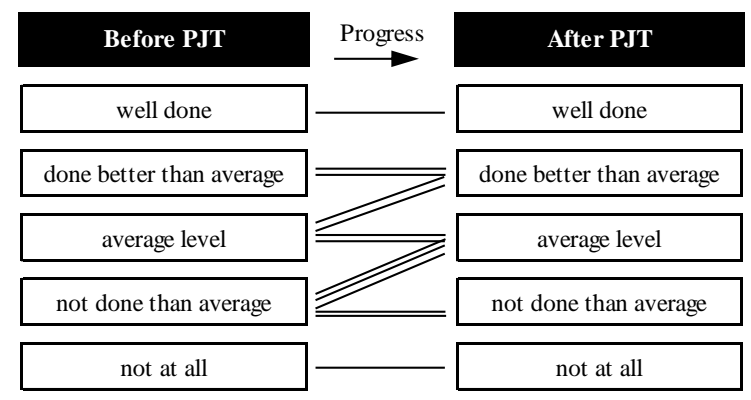

(a) B1: Initiative.

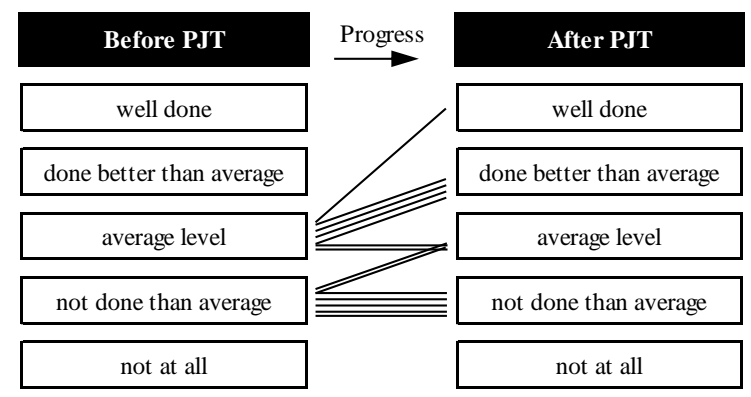

(b) B2: Ability to influence.

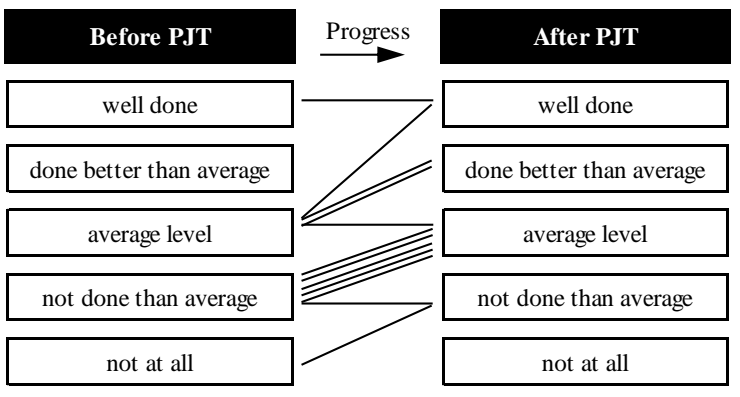

(c) B3: Execution skill.

Fig. 5. Change of students' recognition for "Action" competency.

\section{CONCLUSION}

We conducted the project based on fundamental science and engineering. In this project, we tried to improve the quality of both the process and the product. To succeed projects, however, we recognized that the abilities to enhance the students' recognition was also dispensable. We found that "Fundamental Competencies for Working Person" defined by METI was suitable idea to satisfy these abilities.

From the results of questionnaire by the project students at the end of the project term, it was found that "Fundamental Competencies for Working Person" meaningfully enhanced the students' recognition during completing their project activities. The students especially experienced the importance of "Ability to detect issues", "Creativity", and "Execution skill" through their project activities, because these factors are seemed to be main interests for the project students. They also want to acquire "Planning skill" and "Execution skill" in the near future to improve both the product and the process of the project activities. This means, in other words, that they recognized the lack of these skills to complete their project activities. Most of students recognized that their skills about detecting issues and execution were enhanced through the project activities. Such recognition would become the driving force to challenge the project activities for the students. The skill of creativity was not well- enhanced. The project term of one year seems to be not enough for the project students to accumulate significant experiences, information, and results about the project activities.

We have analyzed the extra-curricular project activities to enhance students' recognition to improve the quality of both the process and the products of projects by applying the idea of "Fundamental Competencies for Working Person". We are planning to continue this study by increasing project samples, and systematize a project style for extra-curricular project activities in university.

\section{REFERENCES}

[1] H. Tarumi, M. Marui, and M. Mika, "Educational impact and learning effectiveness of eco-house design proposal project," KIT Progress, no. 23, pp. 17-30, 2015.

[2] E. Sentoku, S. Iwata, M. Sakamoto, O. Matsushita, M. Ito, M. Shin, N Teraoka, H. Omote, E. Shimbo, and S. Furuya, "Educational impact and learning effectiveness of eco-house design proposal project," KIT Progress, no. 24, pp. 183-192, 2016.

[3] E. Sentoku, M. Shin, M. Sakamoto, and S. Iwata, "Project design program for strengthening student's skills of creativity and innovation," KIT Progress, no. 22, pp. 105-116, 2015.

[4] H. Kamata, K. Nagayama, S. Takechi, K. Nakazawa, and D. Takago, "The collaboration project designing IT applications," KIT Progress, no. 25, pp. 1-10, 2017

[5] H. Kubo, "A proposal of international manufacturing management strategy in photovoltaic industry in Asia," International Journal of the Japan Society for Production Management, vol. 2, no. 1, pp. 37-42, 2014.

[6] Z. Pan and H. Kubo, "Product and process Architecture in white LED industry," International Journal of the Japan Society for Production Management, vol. 2, no. 1, pp. 43-48, 2014.

[7] M. Shinoda, "Improvement of project activities based on method of project management through manufacturing educational material in university," Journal of Economics, Business and Management, vol. 5 , no. 2, pp. 108-111, 2017.

[8] M. Shinoda, K. Nishioka, and A. Mishima, "Systematization of the method of project management for education in university," Journal of International Scientific Publications, vol. 15, pp. 38-47, 2017.

[9] Project Management Institute, A Guide to the Project Management Body of Knowledge: PMBOK Guide, 6th ed. PA: Project Management Institute Inc., 2017.

[10] The Ministry of Economy, Trade and Industry, Japan. Fundamental Competencies for Working Persons. [Online]. Available: http://www.meti.go.jp/policy/kisoryoku/

[11] M. Shinoda and K. Nishioka, "Systematization for improvement of project activities in university by applying project management and fundamental competencies," in Proc. AC-ETel, 2018, pp. 218-226.

Copyright $@ 2019$ by the authors. This is an open access article distributed under the Creative Commons Attribution License which permits unrestricted use, distribution, and reproduction in any medium, provided the original work is properly cited (CC BY 4.0).

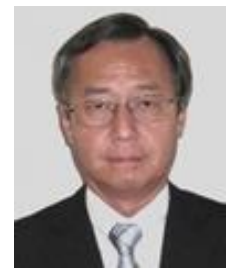

Masahisa Shinoda is a professor of the Mathematics and Science Research Center of Academic Foundations Programs in Kanazawa Institute of Technology, Japan. He received his BS and MS degrees in physics from Osaka University in 1979 and 1981, respectively. He worked for Mitsubishi Electric Corporation from 1981 to 2015 . He was a researcher and an engineer on optical engineering, and was in charge of developing DVD and 
Blu-ray equipment at Mitsubishi. He received his Dr. degree in optical engineering from Osaka Prefecture University in 2001. He was certified as Project Management Professional (PMP) by Project Management Institute (PMI) in 2007. Then, he moved to Kanazawa Institute of Technology (KIT) in 2015. His current research interests are educational engineering and project management.

Prof. M. Shinoda is a member of The Japan Society of Applied Physics, The Optical Society of Japan, The Japanese Society for Engineering Education, and Project Management Institute (USA). He is a senior member of The Institute of Electronics, Information and Communication Engineers (Japan).

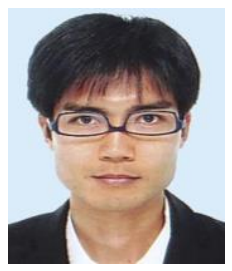

Keita Nishioka is a lecturer of the Mathematics and Science Research Center of Academic Foundations Programs in Kanazawa Institute of Technology (KIT), Japan. He received the BS, MSc and DSc in physics in 2000, 2002, 2005, respectively, from Osaka City University. After completing DSc, he researched the theory of photo-induced phase transition in condensed matter physics at High Energy Accelerator Research Organization in Tsukuba and Institute for Molecular Science in Okazaki for several years. Then, he moved to KIT in 2014. His current research interests are physical education, condensed matter physics and computational physics.

Dr. Keita Nishioka is a member of the Physical Society of Japan and the Japanese Society for Engineering Education. 